\title{
Promoting Continuous Professional Development Among Academics from A Vocational College by Using A Practical Workshop Based on Arduino Technology
}

\author{
Arthur James Swart*, Pierre Eduard Hertzog \\ Central University of Technology, Faculty of Engineering, Built Environment and Information Technology, Bloemfontein, South \\ Africa
}

\begin{tabular}{l} 
A R T I C L E I N F O \\
\hline Article history: \\
Received: 17 November, 2019 \\
Accepted: 27 March, 2020 \\
Online: 04 April, 2020 \\
\hline
\end{tabular}

Keywords:

practice

e-learning

pre-post test

\begin{abstract}
A B S T R A C T
The internet of things has resulted in the design and development of many electronic sensors that need to be integrated with various technologies. Engineering academics need ongoing training relating to this integration as they need to subsequently teach their students. This relates to continuous professional development. The purpose of this article is to illustrate how engineering academics from a vocational college have been able to engage with the theory and practice of sensor integration with Arduino technology, thereby strengthening or reconstructing their conceptual knowledge of these electronic components. A case study is used where experts in electrical engineering designed and facilitated an academic development workshop (2 days in duration) to address a need for continuous professional development. Eighteen academics from a local vocational college attended this workshop where the first goal was to determine their conceptual knowledge of 10 electronic components using an electronic responsive system (pre-test). The second goal was to facilitate a "hands-on" laboratory session where academics had to physically integrate various sensors with an Arduino microcontroller. A post-test online questionnaire was then used to determine their conceptual knowledge again, in order to ascertain the impact of the workshop. Results indicate that their conceptual knowledge was reconstructed with regard to the purpose and use of capacitors, Zener diodes, transformers, ultrasonic sensors, reed switches and passive infrared receivers. A problematic question arose relating to photocells in the first workshop that was held in 2017, which was resolved by the facilitators prior to offering a second workshop in 2018. Positive feedback was received from the participants regarding the relevance and presentation of the workshops. The novelty of this work relates to the design of a practical workshop where all participants are engaged to either strengthen, or reconstruct, their conceptual knowledge regarding electronic components that may be integrated with Arduino technology.
\end{abstract}

\section{Introduction}

This article is an extension of work originally presented at the $12^{\text {th }}$ International Conference on Sensing Technologies, held in Limerick Ireland from 3-6 December 2018. The original paper considered the importance of academic development workshops and focussed on the results of one such workshop that was offered to academics from a vocational college in 2017 [1]. The current article adds to the discussion by highlighting the importance of continuous professional development (as suggested by the reviewers), by detailing the four practical assignments that were

\footnotetext{
* Arthur James Swart, 685 Email : drjamesswart@gmail.com
}

designed for the workshop and by including the results of a second workshop that was offered in 2018. The results of this second workshop are especially important, as a question relating to one of the sensor components caused some confusion among the participants in the first workshop offered in 2017. The revised question attained the goal of strengthening the conceptual knowledge of the participants.

Students or academics need to be engaged on a personal level, where their conceptual knowledge is either strengthened or reconstructed in order to enhance their intellectual capacity, thereby enriching their lives. Reconstructing knowledge refers to identifying gaps or errors in one's thinking, which first needs to be 


\section{A.J. Swart et al. / Advances in Science, Technology and Engineering Systems Journal Vol. 5, No. 2, 452-459 (2020)}

deconstructed before it can be reconstructed again in the correct way. One way of achieving this is by fusing theory and practice, which is mandatory in engineering education $[2,3]$. Students must be allowed to experiment actively in a laboratory, where theory and practice are linked to real-world problems. Academics must be allowed to put into practice their acquired theoretical knowledge (new or old) in an academic development workshop that could lead them to enhancing their teaching practice.

Academic development workshops are successful tools of change in teaching practice and post-workshop evaluations operate as indicators of impact [4]. An academic's teaching practice must be investigated on a regular basis to determine areas of selfimprovement. This forms part of the Scholarship of Teaching and Learning [5] and also of continuous professional development [6]. TVET (technical and vocational education and training) college academics should also engage with this, as they seek to prepare their students to meet the needs of industry, and especially as engineering technicians. Their conceptual knowledge of their field should be strengthened, or reconstructed, on a regular basis, so as to build capacity within the college regarding new technologies. Such expertise is required within any discipline, including electrical engineering, where the study and application of electronic components (including sensors) and microcontrollers is constantly evolving.

Many microcontrollers require a software program to execute commands [7] that can be achieved by significant "hands-on" practice [8]. The internet of things has been defined as a massive network where a diversity of electronic components are used to collect all kinds of data, including sound, light, heat, electricity, mechanics, chemistry, biology, and position [9]. Training academics to effectively integrate many of these electronic components with a specific microcontroller may enable them to teach their students more effectively, and thereby helping academics fulfil their teaching responsibilities. It may further help students to be better equipped to meet the needs of Industry.

The purpose of this research is to illustrate how engineering academics from a vocational college have been able to engage with the theory and practice of sensor integration with Arduino technology, thereby strengthening or reconstructing their conceptual knowledge of these electronic components. The link between academic development workshops and continuous professional development is firstly explained, along with the structure of the practical workshop. The research methodology, results and conclusions then follow.

\section{Academic Development Workshops Linked to Continuous Professional Development}

Research suggests that relevant academic development workshops are critical to enhance the quality of education, as they enable participants to acquire new and innovative teaching and learning practices [10]. Education should never be static. This requires academics to constantly reflect on their teaching practices, seeking innovative ways to improve it. Academic development workshops provide opportunities for such improvement by promoting a culture of reflective practice [11]. These workshops are vital within a dynamic higher education landscape. However, to be effective, they need to be facilitated by experts within a relevant field of study [12]. They should also aim to fuse theory and practice, which may be achieved through a practical workshop. Goals of such workshops must include the transfer of theoretical and technological knowledge, the acquisition of practical handson skills [13] and the reinforcement of conceptual knowledge through practice [1].

A practical workshop regarding the production of Educational videos was held at the University of Huddersfield. This was a 'hands-on' workshop where the participants worked in pairs developing a script and a visual storyboard for their educational videos. Participants learnt about the range of videos and multimedia that can be used in the educational environment and how this could benefit learners [14].

A practical workshop on engineering ethics was held at the University of Nottingham in Malaysia. A post-workshop survey revealed that the participants knowledge on engineering ethics had not significantly improved, but it had motivated them to act more ethically [15].

A further important goal of practical workshops should be to address Continuing Professional Development (CPD). CPD has been defined as the maintenance and enhancement of knowledge expertise and competence of professionals throughout their careers according to a plan that is formulated to meet the needs of an individual [16]. In a $\mathrm{PhD}$ study that explored the impact of short CPD courses on the professional development of teachers, it was found that only one CPD course (duration of one day) focusing on subject-specific information had valuable impacts on the teacher's practice [17].

Demonstration of CPD is increasingly required for recertification of professionals in the workplace [18]. The certification of professional engineers in SA is done by the Engineering Council of South Africa (ECSA). ECSA has an online CPD recording system that consists of 3 main categories, namely development activities, work-based activities and individual activities. Development activities include attending conferences, workshops and colloquiums. Work-based activities include engineering work and mentoring candidate engineering practitioners. Individual activities include supervision of postgraduate students, evaluation of dissertations, publishing research articles and membership of a recognized voluntary association, such as the IEEE. A minimum of 25 credits must be obtained over a five-year cycle to remain registered as a professional Engineer or Technologist. Only ECSA recognised voluntary associations and tertiary institutions with accredited engineering programs may validate CPD developmental activities [19].

\section{Structuring Practical Workshops}

Practical workshops should be bottom-up approaches. They should provide equal engagement by all participants [20]. This can be achieved by using an electronic responsive system (ERS) where individual participant engagement is maintained. Attending a workshop does not guarantee meaningful engagement, as the participant may not actively engage in the discussions due to shyness or distractions. Encouraging active engagement is required to achieve the following primary outcomes of any developmental workshop:

- Agency; individuals need to act voluntarily and independently, making their own decisions [21]. 


\section{A.J. Swart et al. / Advances in Science, Technology and Engineering Systems Journal Vol. 5, No. 2, $452-459$ (2020)}

- Ownership; individuals need to actively participate in decision taking [22].

- Active learning; individuals need to be personally involved [23] by pressing knobs, sketching images, etc.

- Satisfaction of learning; individuals learns from their own misconceptions, as their ideas are shared and scrutinized by others in a "secretive" way [24].

In this research, training is defined as strengthening, or reconstructing, the conceptual knowledge of TVET academics regarding the integration of electronic components with Arduino technology. An academic development workshop, or practical workshop, is used to achieve this aim.

\section{The Practical Workshop Used in This Research}

The practical workshop reported on in this article featured two stages. In stage one, the conceptual knowledge of the participants was reviewed with regard to 10 electronic components (including 5 sensors). In stage two, the software programming skills of the participants were enhanced through repeated practice and interaction with an Arduino microcontroller. The practical workshop was designed by experts in electrical engineering who have published extensively on this topic. Their most recent contributions considered the effective use of Arduino in engineering education [25], the use of Arduino in energy monitoring [26] and the use of Arduino in evaluating the performance of pico-solar systems [27].

The first stage of the workshop required participants to engage with two Microsoft PowerPoint presentations. The main presentation covered the workshop program, learning outcomes and requirements for CPD. Content relating to the purpose and application of 10 electronic components and sensors were also included. A second presentation was designed using Turning Point Software that enables interactivity between the facilitator and participants. This presentation contained a number of multiplechoice questions that were answered in real-time by the participants, in an effort to determine their conceptual knowledge of the selected components and sensors.

This interactive presentation necessitates the use of a transmitter (resembling a calculator) and receiver (USB device connected to a PC). Voluntary responses of each participant (agency involved) is transmitted (active learning as keys need to be pressed) wirelessly to the receiver. Once all responses have been received, then the results are visually displayed on the next slide for all to see and analyse (this contributes to ownership as each contributes to the discussion). Discussions on the real-time results then follows to help the participants to either strengthen their conceptual knowledge of the components and sensors, or to deconstruct and then reconstruct it again (satisfaction of learning occurs as perceptions are shared and compared). These results also enable the facilitator to identify gaps or misconceptions in the thinking of the participants, thereby spending more time clarifying the purpose and application of specific components. The results of this interactive presentation were saved for future analysis.

In the second stage of the practical workshop, the facilitators discussed the basic fundamental theory of the hardware and software associated with the Arduino microprocessor. This included:

- Identifying the key differences between the UNO and MEGA microprocessors;

- Listing the available inputs, outputs and basic connections on the UNO microprocessor;

- Structuring a basic C program in the Arduino integrated development environment (IDE); and

- Reviewing various codes for integrating components and sensors onto the UNO microprocessor.

Four practical assignments were designed for the participants to complete, with each one requiring a specific software program that had to be uploaded to an UNO microprocessor. Four steps had to be followed for each assignment

- Compile a basic software program on the computer;

- Wire the component or sensor to the microprocessor using a breadboard;

- Upload the program using a USB cable; and

- Troubleshoot any errors.

The first assignment required the participants to connect a Liquid Crystal Display (LCD) to the UNO microprocessor where the name of the participant had to be visually shown on the display. The second assignment required the participants to integrate a light dependent resistor (LDR), or photocell, with the UNO microprocessor, where the previously used LCD would now display the resistance value of the LDR. The third assignment required the participants to integrate with the Arduino microprocessor to measure distance and then display it on the LCD. This assignment is described next in detail with regard to the four steps that participants needed to follow. In this way, each assignment built one the first one, as the LCD was subsequently used in all the remaining assignments. This is a form of scaffolding, where support was initially given by the facilitators to the participants regarding the integration of the LCD in the first assignment. However, this support relating to the LCD was withdrawn from subsequent assignments and replaced with support for other components and sensors.

The first step requires a software program code. An example of this code is displayed in Figure 1. In line 1, the LCD library is included and in line 2 the connection pins for the LCD module is defined. The LCD is also defined as a two row LCD with 16 characters per row. The trigger pin of the ultrasonic sensor is also declared as an output and the eco pin as an input. In line 13 of the main loop, the ultrasonic function is called. The measured distance is calculated by this function and placed in the "distance" variable. The cursor position of the LCD is set to row 0 and character 0 where after "Ultrasonic" is written to the LCD. The cursor is then moved to character 0 of the second line and "distance:" is written to the position. The measured distance is then displayed on the $\mathrm{LCD}$, with $\mathrm{mm}$ as the unit. 


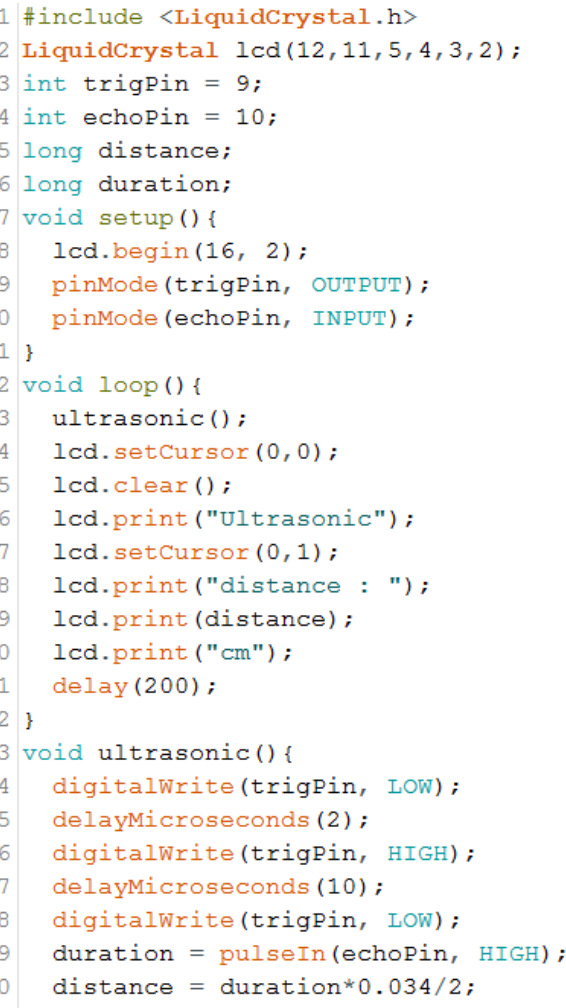

Figure 1: Arduino code for assignment 3

Figure 2 shows the schematic diagram for assignment 3 . The participants use the information in this circuit diagram to physically integrate the required sensors with the Arduino microcontroller with the aid of a breadboard. The Arduino UNO, the LCD and the ultrasonic sensor can be observed in Figure 3 that represents the second step in the assignment, being the wiring of the sensor to the microcontroller. This wiring diagram provides a real-life image of each component, thereby helping the participant to select the correct component from the electronic kit that was provided to them in the laboratory. This diagram is drawn by the participants using a free electronic CAD software, named Fritzing that can be downloaded from the internet. This wiring diagram further assists the participants with fault-finding, as connection mistakes are common. This links to the fourth step of the assignment, namely troubleshooting, that is also required during the third step of the other three assignments.

Step three requires the participants to upload the program to the Arduino microprocessor via the IDE. The participants first need to resolve any errors, as indicated by the IDE (the line in the code that contains the error is highlighted). Common errors that novice programmers make may include format and punctuation in the commands. The commands are also case sensitive, and many errors stem from upper- and lower-case letters. Before uploading, the participants also need to set the output in the IDE to Arduino UNO if the UNO board is used, as there are many boards in the Arduino family. The output port in the IDE also needs to be set to the port that the Arduino UNO is connected to. Many upload errors stem from either wrong board or port selections before uploading the code. The upload process usually takes only a few seconds and, if successful, the program will immediately start executing on the Arduino microprocessor.

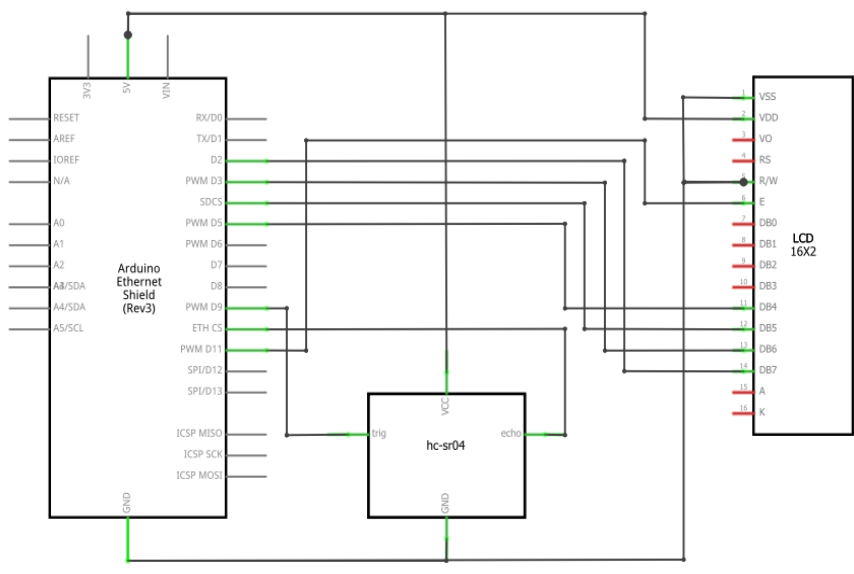

Figure 2: Schematic for assignment 3

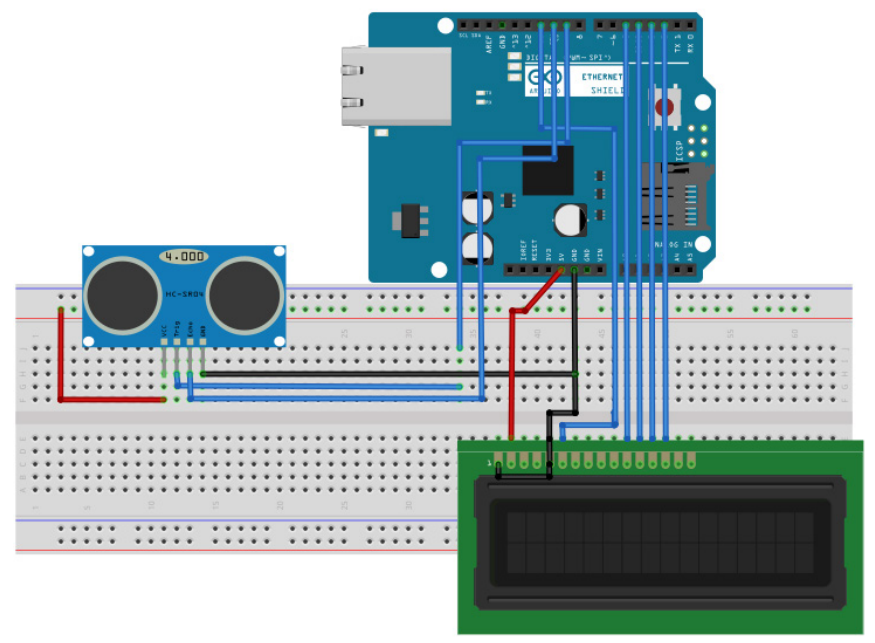

Figure 3: Breadboard for assignment 3

The learning outcome of the fourth assignment required a passive infrared sensor (PIR) and buzzer to be integrated with an UNO microprocessor, where the LCD would indicate an alarm condition. Participants had to again repeat the aforementioned steps for this assignment.

\section{Research Methodology}

A case study is used for this research where the results cannot be generalized. However, a case study can provide practical insights about industry-specific problems that are being addressed and therefore enable learning and changes in practice to occur [28]. In this research, insights into the conceptual knowledge of TVET academics are presented that can impact their workplace practice as they teach and train students in electrical engineering. This knowledge of the participants was either strengthened, or needed to be reconstructed, with regard to 10 electronic components and sensors. The findings of this case study further seek to establish if the designed workshop attained its aim of promoting CPD and if any changes needed to be made to enhance future workshops.

The practical workshop was first presented in 2017 that was attended by 10 TVET academics. The number of participants was limited to 10 to enable more personal attention to be given by the facilitators. This is especially required during the programming 
and troubleshooting stages. A second workshop was presented in 2018 that was attended by 8 TVET academics.

A pre-post test, with no control group, was used to determine the impact of the practical workshop on the conceptual knowledge of the participants. A similar approach has been documented for nursing education [29]. Similar multiple-choice questions were posed for both tests that provided the participants with a predefined list of electronic components and sensors to choose from. Each question was phrased to cover a specific purpose relating to each component. The pre-test was administered during the first stage of the workshop using an ERS. The post-test was administered at the end of the second stage of the workshop using Google Forms. Grades from these tests were analysed quantitatively and are presented in the form of a radar chart. This helps to visually identify which electronic component the participants know well, and which ones require more discussion so that their conceptual knowledge may be reconstructed.

Feedback from the participants was also obtained in the posttest with regard to the facilitators and the workshop. Eight closeended questions were asked using a 5-point Likert scale. The profile of the academics was initially obtained during the first stage of the workshop using the ERS. This also helped to train the participants in using the ERS correctly. The end goal of the profile is to better contextualise the results.

\section{Results and Discussions}

Figure 4 shows the profile of the workshop participants for 2017, while Figure 5 shows the profile for 2018. More than 90\% of the participants were older than 30 years, validating them as academics with life experience. The noted disciplines of the academics validate the relevance of this Arduino based practical workshop, as the majority of the participants $(60 \%+50 \%$ from 2017 and 2018 respectively) were from electrical engineering. It is true that Arduino technology is used by individuals from a wide range of fields, including electrical engineering [25, 30]. The third part of the profile presents the home languages of the participants (right hand side of Figure 4 and Figure 5). Four languages are shown that is not uncommon for SA where 11 official languages are spoken [31]. A dominant language in 2017 was Afrikaans, while in 2018 it was Sesotho. Figure 6 illustrates the perceptions of the participants regarding the workshop facilitators.

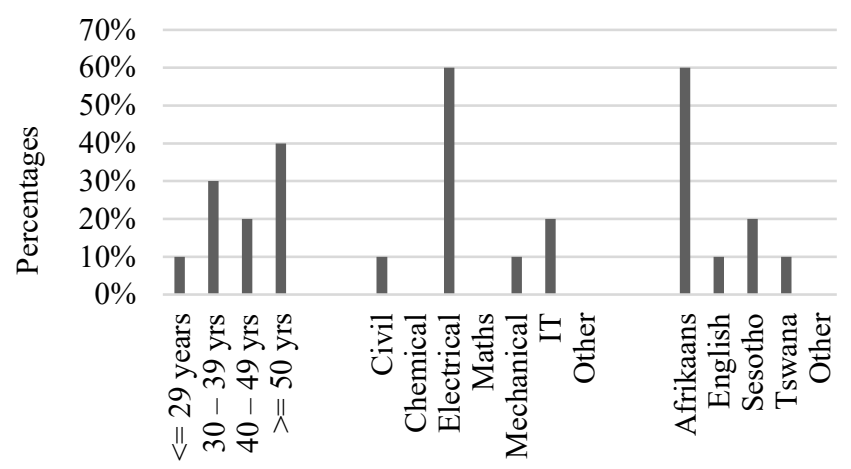

Figure 4: 2017 participant profile

The majority of the participants (67\%) rated their time management skills as very good, while $89 \%$ rated their presentation skills in the same way. $89 \%$ of the participants agreed that the subject knowledge of the facilitators was very good. Finally, $94 \%$ of the participants rated the academic professionalism of the facilitators as very good. Literature suggests that good time management in education is vital [32] as are good presentation skills [33]. It is equally important that a facilitator personally possesses the relevant subject knowledge [12] and academic professionalism (this may include shared values, unselfish concern for others, relevant expertise, logical thinking, use of evidence, conceptual and theoretical rigour and the unbiased pursuit of truth [34].

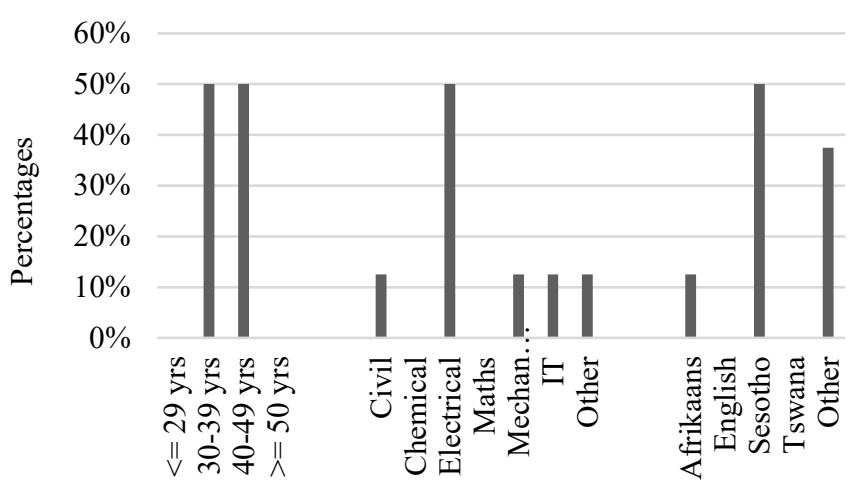

Figure 5: 2018 participant profile

$\square$ Very poor $\quad$ Poor $\quad$ Neutral $\quad$ Good $\quad$ Very good

How would you rate the facilitators time management.

How would you rate the facilitators presentation skills.

How would you rate the facilitators knowledge of the subject.

How would you rate the facilitators academic professionalism.

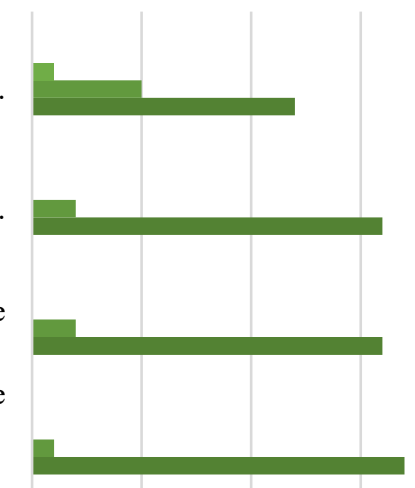

$\begin{array}{llll}0 & 5 & 10 & 15\end{array}$

20

Figure 6: Participant perceptions regarding the facilitators

Figure 7 indicates the perceptions of the participants with regard to the workshop itself. The majority of the participants (94\%) agreed that the workshop venue was appropriate. Appropriate facilities enhance not only the learning process, but also contributes to student satisfaction [35]. Time management is of great importance to academics in TVET colleges who need to cover specific course content in a limited amount of time [36]. Wasting time is therefore not an option. Many of the participants expressed the view that the practical workshop was not a waste of time (83\% disagreed with the given statement). The majority $(61 \%)$ further agreed that the workshop was relevant to their work responsibilities. This correlates well with the disciplines shown in Figure 4 and Figure 5 , where 10 out of the 18 participants $(56 \%)$ came from electrical engineering. However, it further correlates with literature showing the relevance of Arduino in different disciplines [25, 30]. A good indication that the workshop was valuable relates to the fact that $89 \%$ of the participants strongly 
agreed that they would recommend it to their colleagues. Table 1 shows the conceptual knowledge questions that were used in the pre-post test.

$\square$ Strongly disagree $\square$ Disagree $\square$ Neutral $\square$ Agree $\square$ Strongly agree

Would you agree that the venue was appropriate (e.g. lighting, sound and comfort).

Would you agree that this workshop was a waste of time.

Would you agree that this workshop was relevant to your field of study?

Would you recommend that other colleagues attend this workshop?

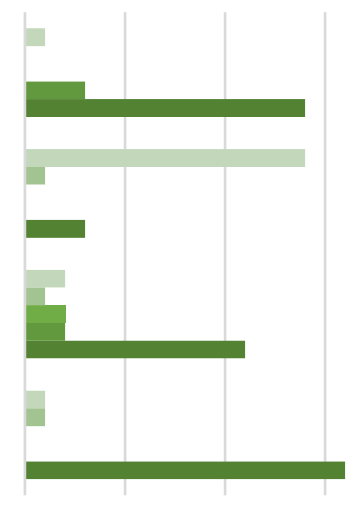

$\begin{array}{llll}0 & 5 & 10 & 15\end{array}$

20

Figure 7: Participant perceptions regarding the workshop

Table 1: Questions used in the pre- and post-test

\begin{tabular}{|c|c|c|}
\hline Number & Questions & Possible choices \\
\hline Q5 & $\begin{array}{l}\text { Allow an AC signal to pass, while } \\
\text { blocking a DC signal }\end{array}$ & Capacitor \\
\hline Q6 & $\begin{array}{l}\text { Reduce the number of electrons } \\
\text { flowing in a circuit }\end{array}$ & Resistor \\
\hline Q7 & Provide voltage regulation & Zener Diode \\
\hline Q8 & $\begin{array}{l}\text { Block direct current in only one } \\
\text { direction }\end{array}$ & Diode \\
\hline Q9 & Isolate two different circuits & Transformer \\
\hline Q11 & $\begin{array}{l}\text { Measure the amount of water in a } \\
\text { JOJO tank }\end{array}$ & Ultrasonic sensor \\
\hline Q12 & $\begin{array}{l}\text { Determine if the door to your } \\
\text { home is open }\end{array}$ & Reed Switch \\
\hline Q13 & Used as a smoke detector & Photocell \\
\hline Q14 & $\begin{array}{l}\text { Switch on a light when a person } \\
\text { enters a room }\end{array}$ & PIR receiver \\
\hline Q15 & $\begin{array}{l}\text { Determine if a car's boot is open } \\
\text { (no magnets available) }\end{array}$ & Tilt sensor \\
\hline
\end{tabular}

The first five questions (Q5 - Q9) focused on basic electronic components, such as the capacitor, resistor, Zener diode, diode and transformer. The next five questions (Q11 - Q15) focussed on sensor based electronic components, including the ultrasonic sensor, reed switch, photocell, PIR and tilt sensor. Participants were expected to engage with the majority of these components during their practical "hands-on" work in the laboratory. Knowledge of these components would be required before they can be correctly applied and connected to an Arduino microprocessor. The pre-test sought to establish the conceptual knowledge of the participants regarding these electronic components, which was then deconstructed (if their initial perceptions were wrong) and then re-constructed during the rest of the practical workshop. The post-test sought to establish whether the participant conceptual knowledge had been strengthened (if their initial perceptions were right) or had been re-constructed.

The pre-test was done at the start of the workshop using an ERS. Immediate feedback of all the participant responses was presented and analysed in order to strengthen or reconstruct relevant conceptual knowledge. The post-test was done at the end of the workshop using Google Forms, as the academics were in a computer-based laboratory with Internet access. The scores for the pre-test (dotted line) and post-test (solid line) for 2017 and 2018 are shown in Figure 8 and Figure 9 respectively.

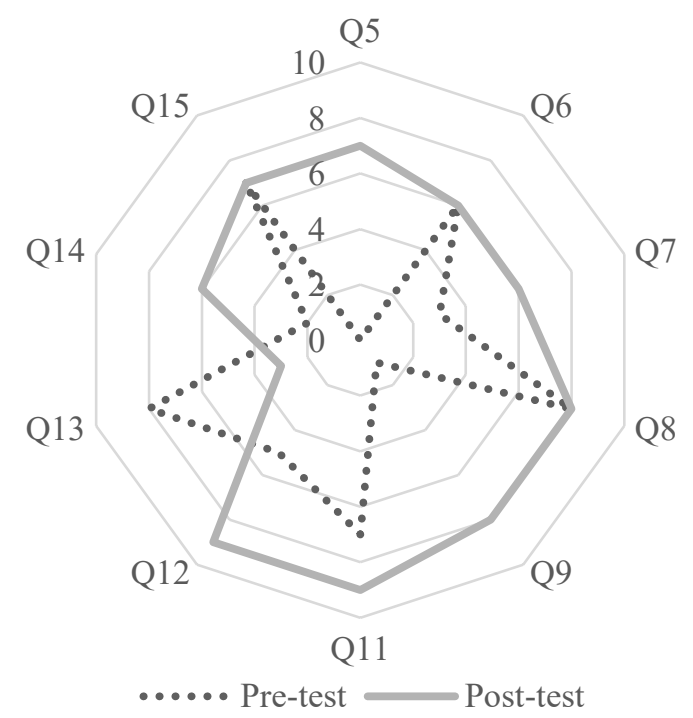

Figure 8: Participant responses to the conceptual knowledge questions for 2017

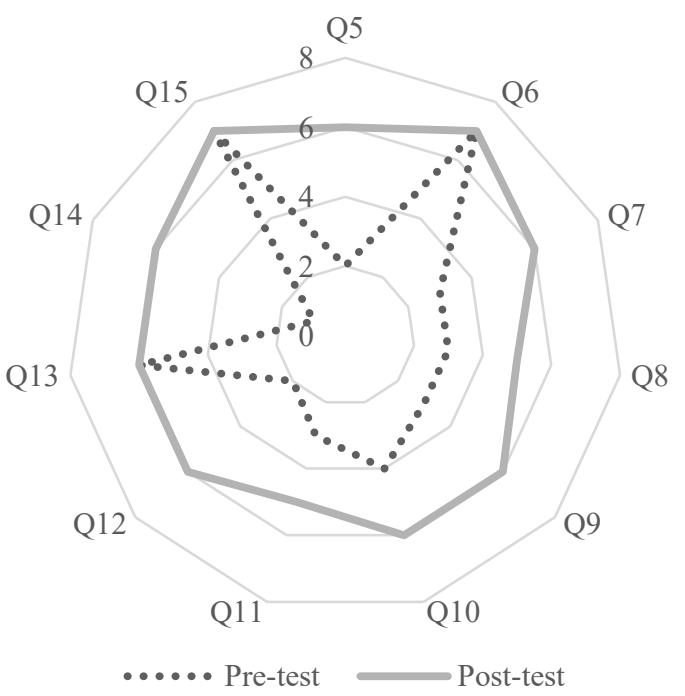

Figure 9: Participant responses to the conceptual knowledge questions for 2018

Questions 5, 7 and 9 indicate that the workshop impacted positively on the conceptual knowledge of the participants regarding the capacitor (Q5), the Zener diode (Q7) and the transformer (Q9). Only a few participants could correctly select the transformer in the pre-test as a component which may be used to 


\section{A.J. Swart et al. / Advances in Science, Technology and Engineering Systems Journal Vol. 5, No. 2, $452-459$ (2020)}

isolate two different circuits. However, the majority of the participants selected the correct answer in the post-test. This suggests that the academics conceptual knowledge was reconstructed. No improvement was noticed regarding resistors (Q6) in both workshops (2017 and 2018). Participants also did not struggle in identifying the purpose of a diode (Q8) in 2017, although this did prove a little challenging in 2018 (3 out of 8 correctly identified the purpose with the pre-test). This may indicate that resistors and diodes are well known, and well used, by these participants.

Question $10(\mathrm{Q} 10)$ was added in the second workshop to incorporate an inductor, as it was missing from the first workshop. Participants struggled to identify its purpose in the pre-test (4 out of 8) while seven participants correctly identified its purpose in the post-test for 2018 .

Questions 11 through 15 relate to other electronic sensors that are commonly integrated with Arduino technology (see Table 1). Improvements in conceptual knowledge are evident for Q11 (Ultrasonic sensor), Q12 (Reed Switch) and Q14 (PIR). This reconstruction of knowledge can surely benefit these academics in terms of improving their own teaching practice. Participants strengthened their conceptual knowledge regarding the tilt sensor (Q15), as they correctly identified its purpose in the pre-test and in the post-test.

Pre-test results for the photocell in 2017 (Q13 in Figure 8) revealed that 8 out of the 10 academics would use it as a light sensor. The question was phrased as follows "Please select the component that you would use for a day/night sensor". Obviously, the participants could associate the term "photo" with "light", and thereby selected the photocell as the desired component. However, the post-test revealed that only 3 academics would use it as a smoke detector, which is a decrease of $50 \%$ from the pre-test with regard to the conceptual knowledge of the participants. The question in the post-test considered a different application for the photocell and was phrased as follows "Please select the component that you would use as a smoke detector". The majority of the participants could not deduce that the presence of smoke would interrupt the reception of light by the photocell, thereby affecting its resistance and triggering an alarm condition. This indicated that more time needed to be allocated to the discussion of the photocell in future workshops and that the facilitators needed to revisit this question in the post-test.

This was done prior to the second workshop that was offered in 2018. The question was revised to state: "Please select the component that you would use to switch a light on when it becomes dark". Phrasing the two questions differently, but using the same application, by using synonyms for the key words' day (being light) and night (being dark) resonated more with the participants. Results in Fig. 9 show NO decrease in the participant's conceptual knowledge for this component (Q13), but an actual strengthening of it. The correct response to the purpose of the photocell, or LDR, was observed for both tests in 2018. Using different applications (day/night sensor versus a smoke sensor) for the same component (photocell) proved a little problematic for the majority of the participants. This can further be addressed in the first stage of future workshops by discussing with the participants a greater variety of applications for each of the electronic components.

\section{Conclusions}

The purpose of this article was to illustrate how engineering academics from a TVET college were able to engage with the theory and practice of sensor integration with Arduino technology, thereby strengthening or reconstructing their conceptual knowledge of these electronic components. A practical workshop, or academic development workshop, was designed and facilitated by experts in electrical engineering. The 2-day workshop consisted of two stages that were presented to 18 academics from a TVET college in SA during 2017 and in 2018. The first stage sought to obtain the conceptual knowledge of TVET academics relating to 10 electronic components and sensors using a pre-test. The second stage related to four practical assignments that the participants needed to complete in a laboratory, followed by an online post-test that was again used to determine their conceptual knowledge. This was done to determine the value, and impact, of the practical workshop.

Conceptual knowledge regarding capacitors, Zener diodes, transformers, ultrasonic sensors, reed switches and PIR had to be deconstructed, and then reconstructed again during the workshop for many of the participants. However, their conceptual knowledge regarding photocells deteriorated in 2017, requiring the facilitators to review their discussion on it. This was done before the second workshop was offered in 2018. The results of the revised question showed no decrease in the participant's conceptual knowledge for this component in 2018, but an actual strengthening of it. A key recommendation in this regard is to retain the same application for each electronic component between the pre-test and post-test. However, synonyms or different phrases could be used between the two questions. Another option is to enhance the discussion after the pre-test, but before the post-test, by providing participants with a greater variety of applications for each of the electronic components.

Conceptual knowledge regarding resistors, diodes and tilt sensors were strengthened, as the results between the pre- and posttest remained similar. TVET academics further indicated that the practical workshop was relevant to their work and that they would encourage fellow colleagues to attend future workshops.

A limitation of this study is related to the small sample size, where only 18 TVET college academics attended the workshops. However, the research methodology chosen was a case study that aims to explore and describe a setting where the researcher can gain a more in-depth understanding of what he/she is seeking. In this research, the facilitators were seeking to determine if the practical workshop (the setting) that they designed would be able to help TVET college academics to strengthen, or reconstruct, their conceptual knowledge of electronic components that may be integrated with the Arduino technology. This was achieved as only one question had to be rephrased in the pre and post-test. Subsequent offerings of this practical workshop should therefore not present any major challenges with regard to determining conceptual knowledge, as it has been validated on two occasions.

It is recommended that more such academic development workshops be offered as practical workshops by field experts to 


\section{A.J. Swart et al. / Advances in Science, Technology and Engineering Systems Journal Vol. 5, No. 2, $452-459$ (2020)}

enable fellow academics to either strengthen, or reconstruct, their conceptual knowledge of relevant technologies. This would also greatly contribute to meeting the requirements of $\mathrm{CPD}$, as required by professional engineering bodies around the world.

\section{Conflict of Interest}

The authors declare no conflict of interest.

\section{Acknowledgment}

The authors wish to acknowledge the financial support of the Manufacturing, Engineering and Related Services SETA (merSETA) in South Africa.

\section{References}

[1] Swart, A. J. and Hertzog, P. E., "Engaging academics from an engineering training college with Arduino sensors using an academic development workshop," presented at the ICST 2018, 12th International Conference for Sensing Technology, Limerick, Ireland, 2018.

[2] Grinter, L. E., "Responsibility in engineering education," The Journal of Higher Education, 25(5), 258-261, 1954.

[3] Swart, A. J., "Does it matter which comes first in a curriculum for engineering students - theory or practice?," IJEEE, International Journal of Electrical Engineering Education, 47(2), 189-199, 2010. DOI:10.7227/IJEEE.47.2.8.

[4] McCulloch, A. and Loeser, C., "Does research degree supervisor training work? The impact of a professional development induction workshop on supervision practice," Higher Education Research \& Development, 35(5), 968-982, 2016.

[5] Swart, A. J., Luwes, N., Olwagen, L., Greyling, C., and Korff, C., "Scholarship of teaching and learning - "What the hell" are we getting ourselves into?," EJEE, European Journal of Engineering Education, 42(6), 653-667, 2016. DOI:10.1080/03043797.2016.1214689.

[6] Mardapi, D. and Herawan, T., "Community-Based Teacher Training: Transformation of Sustainable Teacher Empowerment Strategy in Indonesia," Journal of Teacher Education for Sustainability, 21(1), 48-66, 2019. DOI: $10.2478 /$ jtes-2019-0004.

[7] Umelo, N., Amadi, A., Obodoeze, F., and Onyibe, C., "A Multi-purpose Hardware Efficient Temperature Regulator with LCD Display," International Journal of Computer Engineering and Information Technology, 9(10), 254-257, 2017.

[8] Yüksekkaya, M. and Haberal, O. E., "An Efficient Microcontroller Course With An Affordable And Easy To Use Development Setup," presented at the EPESS, The Eurasia Proceedings of Educational \& Social Sciences, 2015.

[9] Fan, Y. B. and Liu, H., "Study on Application Model of Internet of Things for Green Manufacturing," Applied Mechanics and Materials, 484(1), 187190, 2014. DOI:10.4028/www.scientific.net/amm.484-485.187.

[10] Vorster, J. and Quinn, L., "Privileging knowledge, creating knowers: An analysis of a formal programme for university lecturers," Re-Imagining Academic Staff Development: Spaces for Disruption, edited by L. Quinn), 71-88, 2012.

[11] Ndebele, C., "Deconstructing the narratives of educational developers on the enabling and constraining conditions in their growth, development and roles as educational staff development facilitators at a South African University," International Journal of Educational Sciences, 6, 103-115, 2014. DOI:10.1080/09751122.2014.11890123.

[12] Makondo, L. and Makondo, O., "The Interplay between South African Higher Education Context and Academic Development," Anthropologist, 17(2), 301-309, 2014. DOI:10.1080/09720073.2014.11891438.

[13] Swart, A. J., "Distance Learning Engineering Students Languish Under Project-Based Learning, But Thrive in Case Studies and Practical Workshops," IEEE Transactions on Education, 59(2), 98-104, 2016. DOI:10.1109/TE.2015.2453349.

[14] Gibbs, G. R., "Workshop: Producing educational videos: design and workflow issues," presented at the Inspire Conference, HEA Social Sciences Conference, The Studio, Manchester, 2015.

[15] Ooi, P. C. and Tan, M. T., "Effectiveness of workshop to improve engineering students' awareness on engineering ethics," Procedia-Social Behavioral Sciences, 174(2015), 2343-2348, 2015. DOI:10.1016/j.sbspro.2015.01.898.
[16] Manley, K., Martin, A., Jackson, C., and Wright, T., "A realist synthesis of effective continuing professional development (CPD): A case study of healthcare practitioners' CPD," Nurse education today, 69, 134-141, 2018. DOI:10.1016/j.nedt.2018.07.010.

[17] Cole, M. J., "An Exploration of the Long-Term Impacts of Short CPD Workshops," PhD, Northumbria University, 2018.

[18] Mack, H. G., Golnik, K. C., Murray, N., and Filipe, H. P., "Models for implementing continuing professional development programs in lowresource countries," MedEdPublish, 6, 1-18, 2017. DOI:10.15694/mep.2017.000018.

[19] Cruywagen, H., "Continuing professional development for the quantity surveying profession in South Africa:: commentary," Acta Structilia: Journal for the Physical Development Sciences, 14(2), 91-103, 2007. DOI:hdl.handle.net/10520/EJC110013.

[20] Kasimba, R., "Training and Development Programs in Educational Institutions: A Human Factor Approach," Journal of Gleanings from Academic Outliers, 3(1), 64-86, 2014.

[21] Altbach, P., "Higher education and the WTO: Globalization run amok," International Higher Education, 23, 2-4, 2015.

[22] Shapiro, J. P. and Stefkovich, J. A., Ethical leadership and decision making in education: Applying theoretical perspectives to complex dilemmas. New York: Routledge. 2016.

[23] Spooner, E., Interactive Student Centered Learning: A Cooperative Approach to Learning. Lanham: Rowman \& Littlefield. 2015.

[24] Ryan, M. and Ryan, M., "Theorising a model for teaching and assessing reflective learning in higher education," Higher Education Research \& Development, 32(2), 244-257, 2013. DOI:10.1080/07294360.2012.661704.

[25] Hertzog, P. E. and Swart, A. J., "Arduino - Enabling engineering students to obtain academic success in a design-based module!," presented at the EDUCON 2016, IEEE Global Engineering Education Conference, Abu Dhabi, UAE, Dusit Thani Hotel, 2016.

[26] Swart, A. J. and Hertzog, P. E., "LED's as viable power loads for experimental purposes relating to PV modules in pico-solar systems," presented at the ICETAS 2017, AMA International University Bahrain, Bahrain, 2017.

[27] Swart, A. J. and Hertzog, P. E., "Evaluating the Performance of Small-Scale PV Modules in a Semi-Arid Area to Identify any Anomalies," IJST, Indian Journal of Science and Technology, 12(28), 1-9, 2019. DOI:10.17485/ijst/2019/v12i28/147001

[28] Love, P. E., Zhou, J., and Matthews, J., "Project controls for electrical, instrumentation and control systems: Enabling role of digital system information modelling," Automation in Construction, 103, 202-212, 2019. DOI:10.1016/j.autcon.2019.03.010.

[29] Neafsey, P. J., "Computer-assisted instruction for home study: a new venture for continuing education programs in nursing," The Journal of Continuing Education in Nursing, 28(4), 164-172, 1997. DOI:10.3928/0022-012419970701-06.

[30] Schlingloff, B.-H., "Towards a curriculum for model-based engineering of embedded systems," in Tagungsband des Dagstuhl-Workshops, H. Giese, et al., Eds., ed Munchen: fortiss GmbH, 2014, pp. 83-90.

[31] Robertson, S.-A. and Graven, M., "Exploring South African mathematics teachers' experiences of learner migration," Intercultural Education, 26(4), 278-295, 2015. DOI:10.1080/14675986.2015.1071754.

[32] Kirillov, A. V., Tanatova, D. K., Vinichenko, M. V., and Makushkin, S. A. "Theory and practice of time-management in education," Asian Social Science, 11(19), 193-204, 2015. DOI:10.5539/ass.v11n19p193.

[33] Hori, T. and Alley, M., "W-10 Rethinking Oral Presentations for Engineers in a Global Society," presented at the JSEE, Japanese Society for Engineering Education Annual Conference, Tokyo City University, Setagaya Campus, 2017.

[34] Kolsaker, A., "Academic professionalism in the managerialist era: A study of English universities," Studies in Higher Education, 33(5), 513-525, 2008. DOI: $10.1080 / 03075070802372885$.

[35] Hanssen, T.-E. S. and Solvoll, G., "The importance of university facilities for student satisfaction at a Norwegian University," Facilities, 33(13), 744759, 2015. DOI:10.1108/F-11-2014-0081.

[36] Buthelezi, Z. and Training, "Lecturer experiences of TVET College challenges in the post-apartheid era: a case of unintended consequences of educational reform in South Africa," Journal of Vocational Education, 70(3), 364-383, 2018. DOI:10.1080/13636820.2018.1437062. 